Please send trade news information and illustrations to Arveen Bajaj at the BDJ, 64 Wimpole Street, London W1G 8YS. Trade news is supplied as a service to the reader and does not imply endorsement by the BDJ. Normal and prudent research should be exercised before purchase of use of any product mentioned.

\section{TRADE NEWS}

WHAT'S NEW

\section{New kit available}

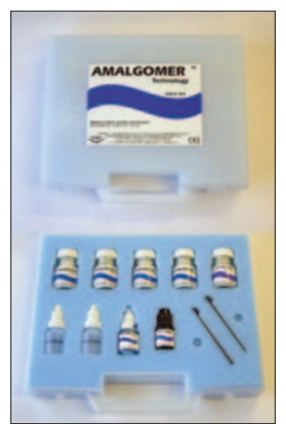

Amalgomer restoratives are now available in a new introductory kit. The intro kit contains 4 Amalgomer anterior shades and 1 Amalgomer CR universal posterior.

Also included are the new dentine conditioner liquid and light cure varnish, as well as full directions for use and all the accessories required to successfully complete the restoration with the product.

Presented in a tough and durable plastic case, this kit is designed to last with individual Amalgomer powders being replaced as and when necessary.

The product is available from Advanced Healthcare Ltd.

Reader response number 50

\section{Tough workwear}

A range of workwear for those employed in the healthcare sector has recently been launched. The DiBianco Professional Clothing Collection caters for both men and women and consists of a selection of tunics, work coats, dresses, polo and Tshirts, tabards, trousers, a skirt, a lightweight fleece jacket and a fleece bodywarmer. Ten classic styles of footwear are also available.

The textiles used in the garments' construction are tested for their resilience to

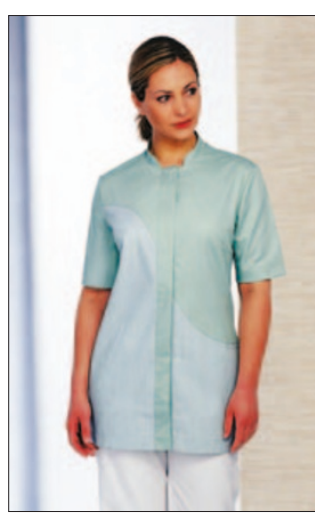

frequent laundering to ensure they retain their shape and colour. DiBianco's in-house embroidery service can provide the name of the dental practice applied to the garments.

Reader response number 51
New root canal preparation cream

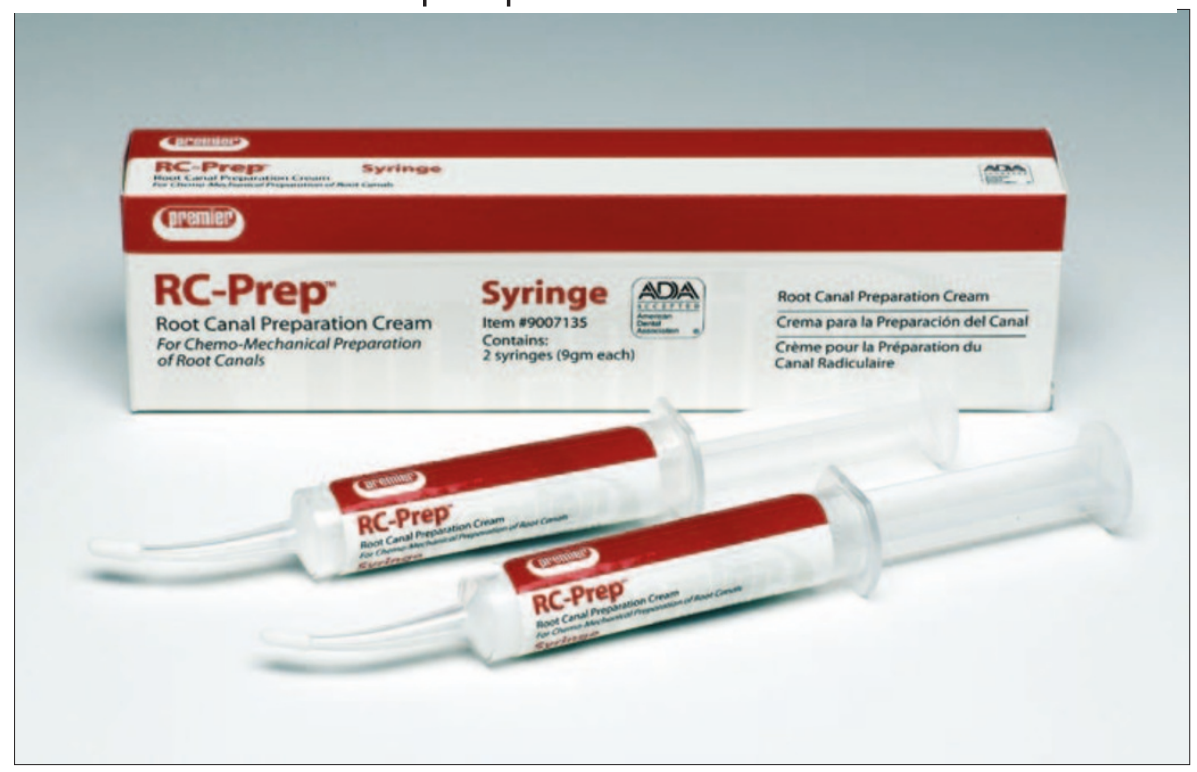

RC-Prep has recently become available in the UK. A formulation of glycol, urea peroxide and EDTA in a special water-soluble base, it can be used to help remove calcifications while whitening, deodorising and lubricating the canal to permit more efficient instrumentation, according to the company.
It can be used with finger or enginedriven instruments and allows reamers and files to move easily without binding. The manufacturer claims it can also be used with apex locators as it permits reliable readings. RC-Prep is supplied in packs of $2 \times 9 g m$ syringes.

Reader response number 52

\section{Single dose syringes}

New Fill-In Unidose single dose syringes from KerrHawe are a new concept in the fabrication of temporary crowns, bridges and veneers, according to the manufacturer.

It claims that utilising a high filler loading to around 53\% gives the Fill-In a low shrinkage value.

A new pre-poly-

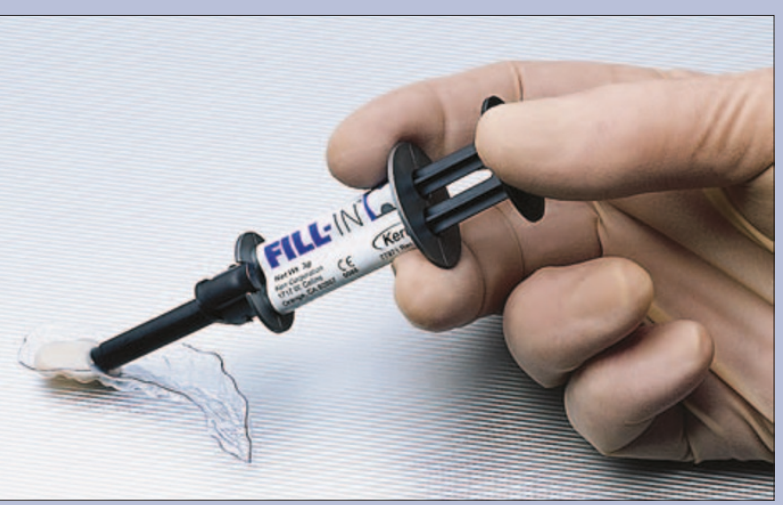

merised filler technology, KerrHawe has also developed the product to offer a reduced sticky (air inhibited) layer upon setting, therefore aiding easier and faster polishing. The product is similar in cost per use as conventional cartridge delivery and the all-inone delivery means that there are no mixing tips or dispensing guns to disinfect after use.

Reader response number 53 


\section{INFECTION CONTROL}

\section{Protecting surfaces}

The Disposa-Shield range from Dentsply consists of a number of products which can be used to protect various surfaces in the surgery.

The product offers barrier protection, according to Dentsply and is available in five different varieties.

The range consists of a self-adhesive sheet for light handles and control panels, a cover for airmotor and air/water syringes and one for tubing/turbine heads.

In addition there is one for headrests and X-ray heads and also for Cavitron handpieces.

Reader response number 54

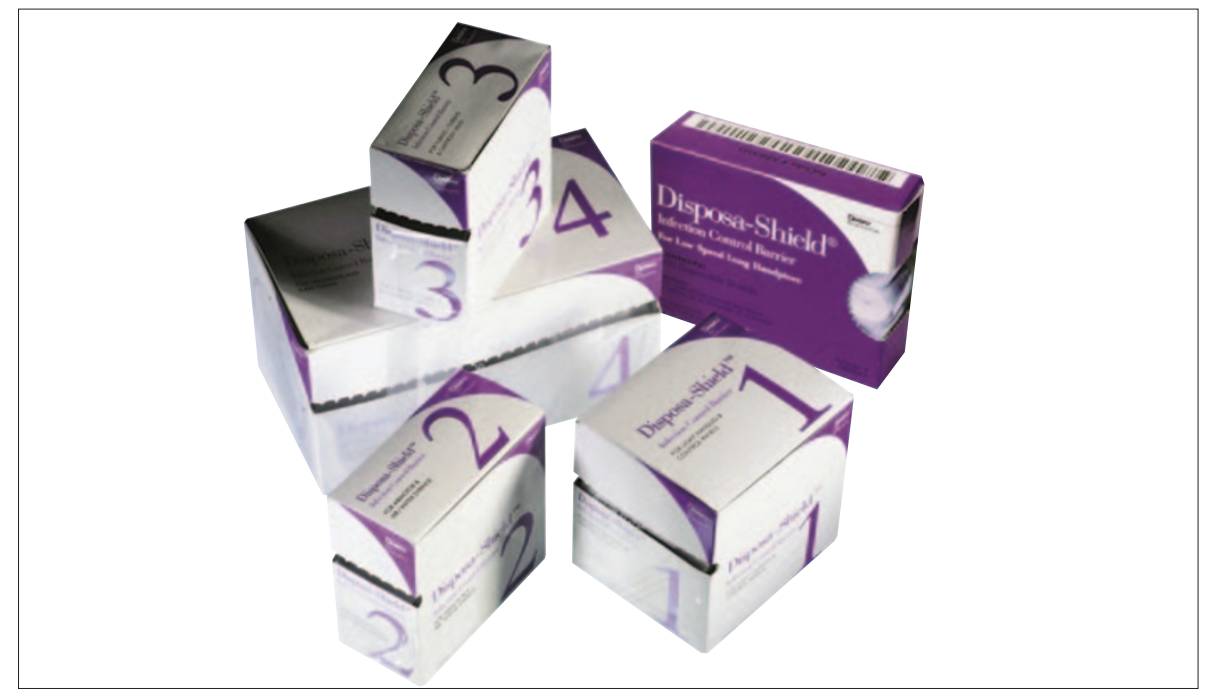




\section{Disinfecting instruments}

Dürr Dental has a range of hygiene products for disinfecting instruments. The ID 212 can be used for general instrument cleaning as well as for rotating instruments that are sensitive to alkali and alcohol. For cleaning rotary instruments there is ID220, an aldehyde-free disinfectant.

The company also manufactures its own disinfectant box made of tough polypropylene that can be used to disinfect various instruments. It can be filled to one of three capacities depending on the size and quantity of items to be sterilised. The design of the box is such that instruments are easy to drain (which prevents them from becoming

interlocked) and is easy to carry when full avoiding spillage, according to the company.

Reader response number 55

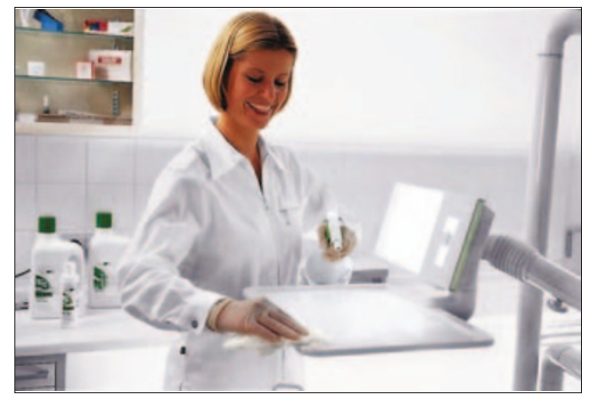

\section{Surface cleaning}

DE Healthcare's Safe R Surface is a cleaning solution for alcohol compatible surfaces and equipment within the dental surgery.

An aldehyde free solution, it is supplied in a variety of packages including 1 litre and 5 litres without spray head, 1 litre spray dispenser, 20ml hand pump for 5 litres and 20ml tap for 5 litres.

Available form Kent Express, it can be used by wetting the surfaces or equipment and allowing the product to react.

Reader response number 57

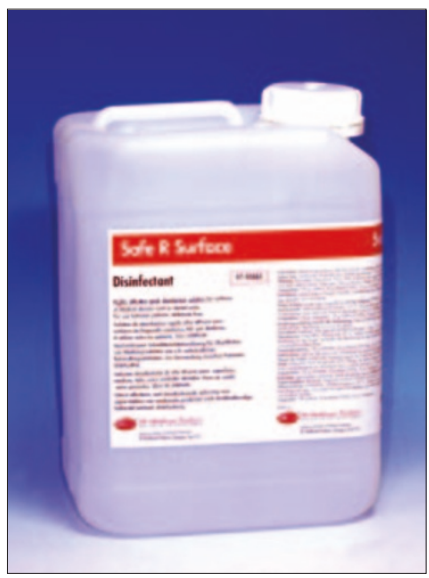

\section{Flameless burner alternative}

No Flame R Plus is a safe alternative to the use of spirit lamps and alcohol/gas burners in the dental practice, according to Zahn Laboratories. The unit heats using the principle of induction.

Activated by a sensor which reacts to instruments containing steel, the unit heats instruments placed into the coil opening. The company claims that no gas supply is required, there are no risk of burns or fire danger and the unit does not burn oxygen or emit heat into the environment.

Reader response number 56

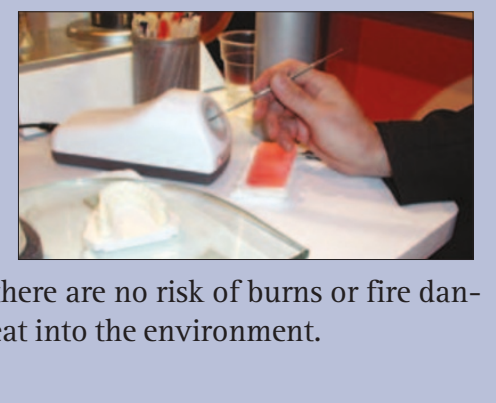




\section{Full range of instrument cleaners}

The complete Miltex range from Salvin includes the EZ-Zyme Multi-Enzyme Instrument Cleaner which dissolves blood and tissue (both lipid and protein) as part of the instrument pre-soak. Biodegradable and with a neutral $\mathrm{pH}$, it can also be used in an ultrasonic cleaner or evacuation system cleaner.

Similarly the Surgical Instrument Cleaner Concentrate has a neutral $\mathrm{pH}$ formula and makes 32 gallons when diluted. The Surgical Instrument Spray Lubricant

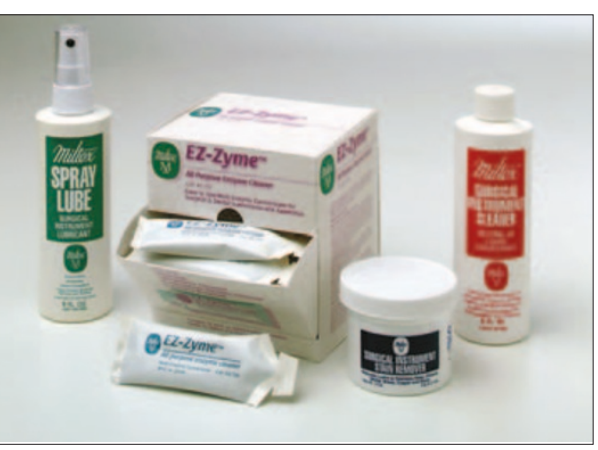
is an 'instrument milk' in a spray. Non greasy and anti-corrosive it is designed for use on hinged instruments where it helps preserve instrument life and keep scissors etc sharp.

Finally the Instrument Stain Remover removes stains and tarnish without harming instrument surfaces. The range is available from General Medical. Reader response number $\mathbf{5 8}$

\section{Disinfecting impressions and dentures}

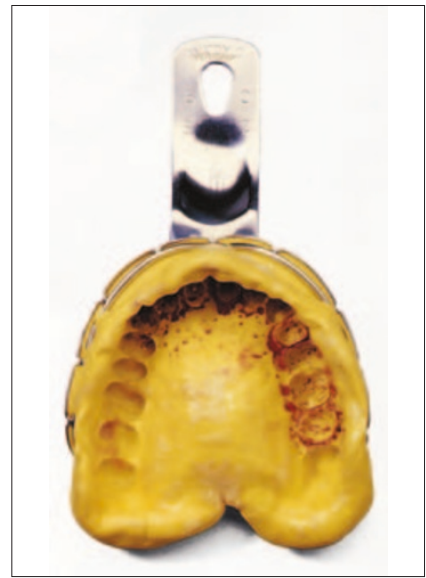

Dürr Dental manufactures a range of cleaning and disinfectants specifically for use on impressions and dentures. MD520 has a wide range of applications, and can be used on alginates, silicones, polyether rubber, hydrocolloids and polysulphides.

According to Dürr Dental, no reduction in the dimensional stability or plaster compatibility occurs and it is effective against a wide spectrum of bacteria, fungi and viruses.

All its hygiene products are colour coded to identify each product's application - blue for instruments, green for surfaces, pink for skin and hands and yellow for special areas such as suction systems and amalgam separators.

Reader response number 59

\section{Decontamination of water supply units}

Alkazyme-W is a suitable cleanser and disinfectant agent for use in the routine decontamination of chair-side integral water supply units. The combined enzyme based detergent disinfectant system in Alkazyme- $W$ rapidly removes harmful bio-film leaving all internal surfaces thoroughly clean and disinfected, according to the company.

It is available from Henry Schein in 500g containers of concentrated powder and is supplied with a $5 \mathrm{mg}$ dosage spoon. $5 \mathrm{mg}$ of powder dissolves in 1 Litre of water to make the full strength solution.

Reader response number 60

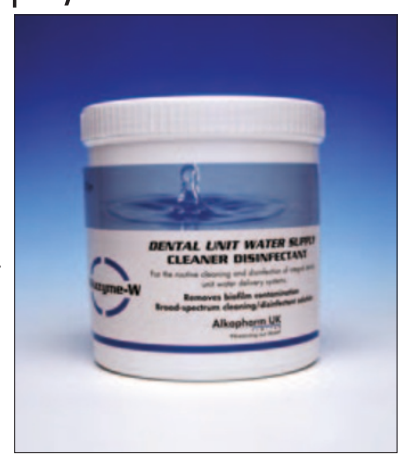

\section{Air-water syringe}

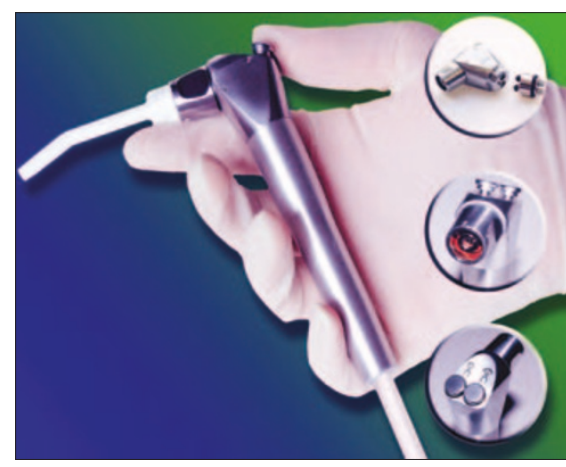

A new autoclavable air-water syringe is available from Ivoclar Vivadent that may be fitted to air and water lines and is engineered to accept the Pro-Tip disposable syringe tips.

The new air-water Pro-Syringe is a combination of a standard syringe and a standard form of Pro-Tip converter, with a designed attachment interface which enables operation as a dedicated Pro-Tip syringe. After each patient, the Pro-Tip is discarded and the ProSyringe head is disconnected for autoclaving. Reader response number 61 